\title{
Darlings: Indirect Labour and Idle Time
}

\author{
Nadine Norman
}

(in collaboration with some other "Darlings")

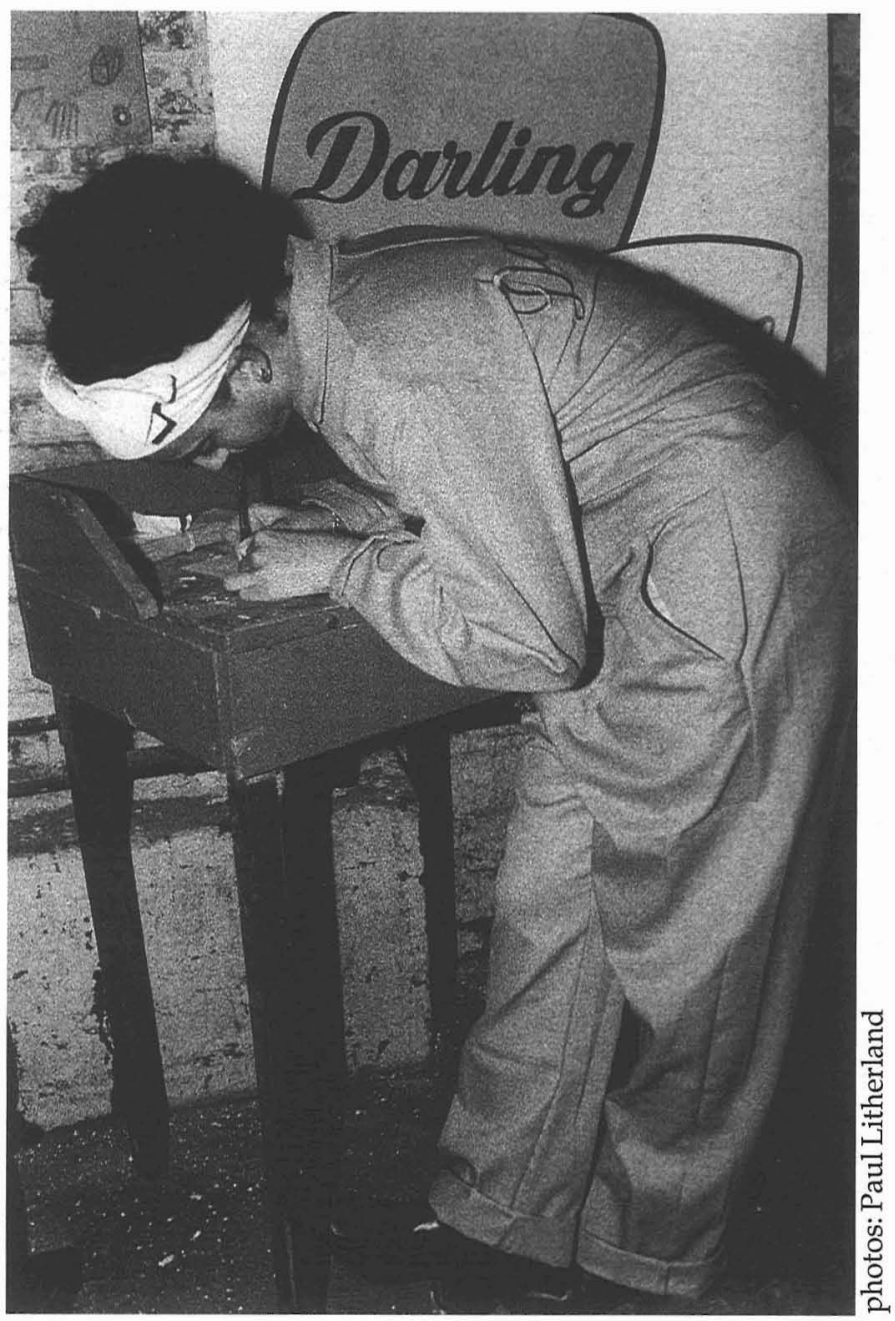

a performance/installation at the Darling Brothers Foundry, Montreal, 1997 
Darlings: Indirect Labour and Idle Time · 63

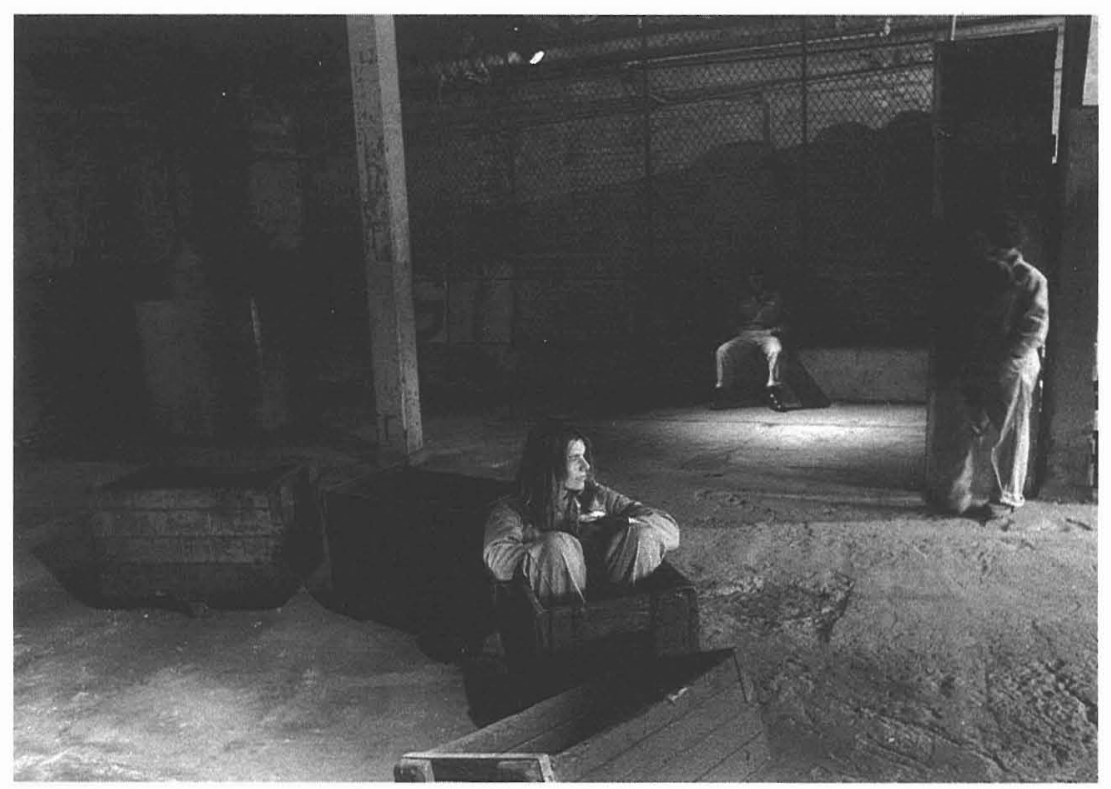



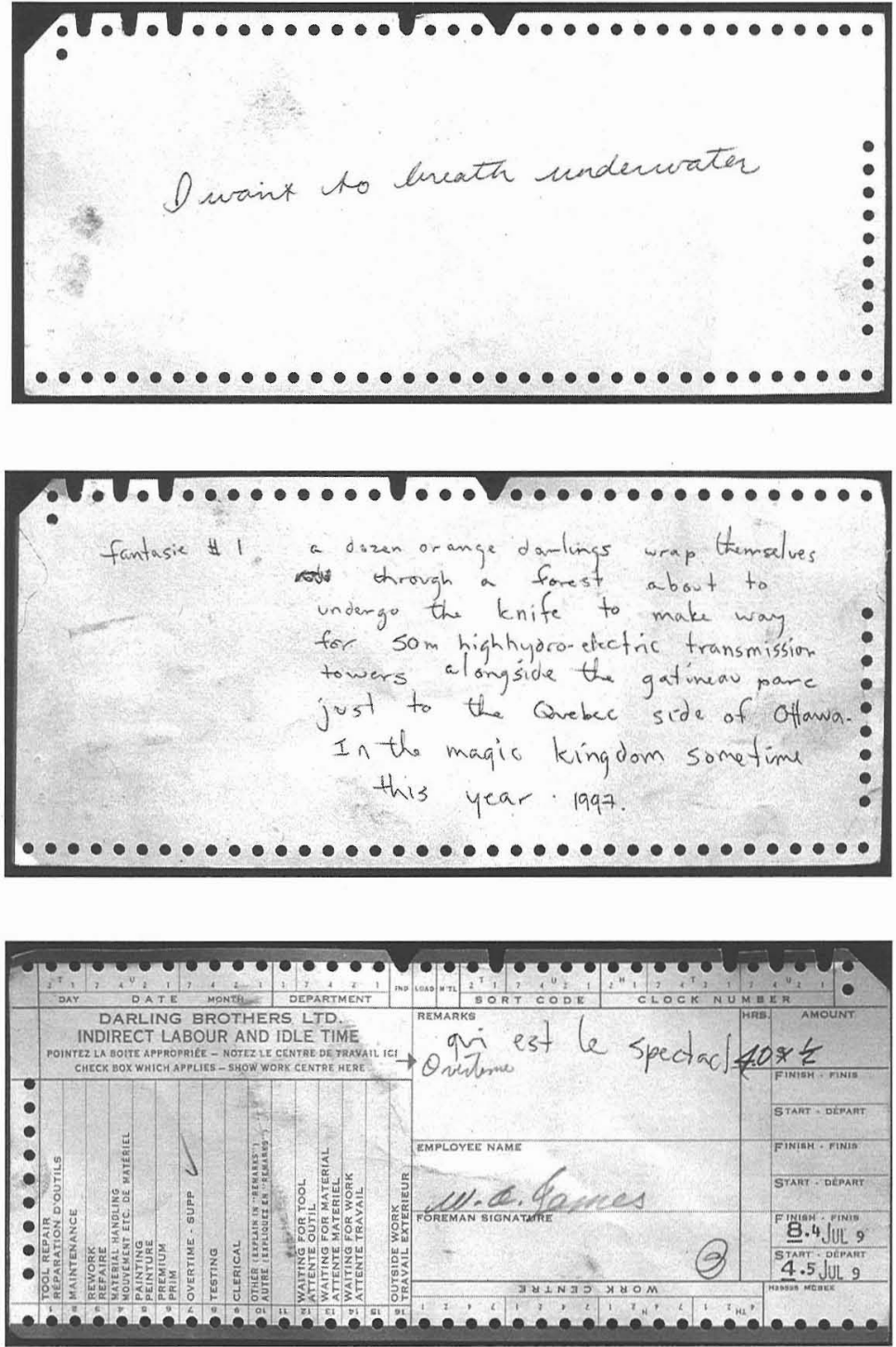